\title{
A Polyphenylene Support for Pd Catalysts with Exceptional Catalytic Activity**
}

\author{
Feng Wang, Jerrik Mielby, Felix Herrmann Richter, Guanghui Wang, Gonzalo Prieto, \\ Takeshi Kasama, Claudia Weidenthaler, Hans-Josef Bongard, Søren Kegnaes, Alois \\ Fürstner, Ferdi Schüth*
}

\begin{abstract}
We describe a solid polyphenylene support as an excellent platform for metal catalyzed reactions, which are normally carried out under homogeneous conditions. The catalyst is synthesized via palladium catalyzed Suzuki coupling which directly results in formation of palladium nanoparticles confined to a porous polyphenylene network. The composite solid is in turn highly active for further Suzuki coupling reactions, including non-activated substrates that are challenging even for molecular catalysts.
\end{abstract}

A major goal in catalysis is to combine the advantages of molecular catalysts and heterogeneous processes, ideally maintaining - or even improving - the reactivity and selectivity of the molecular catalysts, while facilitating product recovery and catalyst recycling. ${ }^{[1-3]}$ However, in fine chemicals synthesis molecular catalysts are predominantly used, partly due to the fact that typical solids do not provide the non-polar environments which are often required for organic reactions. This is often easier realized with metal complexes and suitable ligands and solvents, which provide the required geometry and stabilize the transition state of the reaction. ${ }^{[4-6]}$ Polymers as less conventional supports could create a 'solvent'-like organic reaction environment, onto which ligands and

[*] Dr. F. Wang, Dr. F. H. Richter, Dr. G. H. Wang, Dr. G. Prieto, Dr. C. Weidenthaler, H.-J. Bongard, Prof. Dr. A. Fürstner, Prof. Dr. F. Schüth

Max-Planck-Institut für Kohlenforschung

D-45470 Mülheim an der Ruhr, Germany

Fax: (+) 49208 306-2995

E-mail: schueth@kofo.mpg.de

J. Mielby, Prof. Dr. S. Kegnæs

Department of Chemistry

Technical University of Denmark

DK-2800 Kgs. Lyngby, Denmark

Dr. T. Kasama

Center for Electron Nanoscopy

Technical University of Denmark

DK-2800 Kgs. Lyngby, Denmark

[**] This work was conducted in the framework of the ERC Advanced Grant project "POLYCAT". In addition, it was funded by the Cluster of Excellence RESOLV. F.W. and G.P. are grateful to the Alexander von Humboldt Stiftung for financial support. The A.P. Møller and Chastine Mc-Kinney Møller Foundation are gratefully acknowledged for their contribution toward the establishment of the Center for Electron Nanoscopy in the Technical University of Denmark.

Supporting information for this article is available on the WWW under http://dx.doi.org/10.1002/anie.201xxxxxx.((Please delete if not appropriate)) metal complexes can be grafted to provide the catalytic functionality. ${ }^{[7,8]}$ Polymeric solids based on polystyrene, ${ }^{[9,10]}$ polydivinylbenzene (PDVB), ${ }^{[11]}$ polyacrylate derivatives, ${ }^{[12]}$ covalent organic frameworks $(\mathrm{COF})^{[13]}$ or hybrid metal-organic frameworks ${ }^{[14-16]}$ have recently been explored as carriers for catalytic metal nanoparticles.

Commercially, polymeric catalyst supports are limited to ionexchange resins, e.g. the Amberlyst ${ }^{\circledR}$ series based on polystyreneco-divinylbenzene. Also carbon materials are widely applied when an apolar carrier material is required to host metal catalytic functionalities. ${ }^{[17]}$ In our search for intermediate materials between carbons and the polymers listed above, we decided to study the performance of polyphenylene (PPhen) in catalysis. In this polymer, all the carbon atoms are $s p^{2}$ hybridized. The thermal and chemical stability of PPhen is higher than those of most other polymers, while it still provides a "solvent-like" reaction environment, suggesting its suitability for organic transformations.

The catalyst consists of Pd-nanocrystals supported on a porous polyphenylene network, and is synthesized by palladium catalyzed cross-coupling of 1,2,4,5-tetrabromobenzene and benzene-1,4diboronic acid. ${ }^{[18,19]}$ The cross-coupling catalyst, tetrakis(triphenylphosphine)palladium $\left(\mathrm{Pd}\left(\mathrm{PPh}_{3}\right)_{4}\right)$, was found to decompose at $150{ }^{\circ} \mathrm{C}$ in dimethylformamide into palladium nanocrystals with a broad particle size distribution, from sub-5 nm to several tens of nm (Figure S1). Combining the decomposition of the palladium complex with the in situ catalyzed C-C coupling polymerization reaction allows confinement of the nascent Pdparticles in the developing polymer network (Scheme 1).

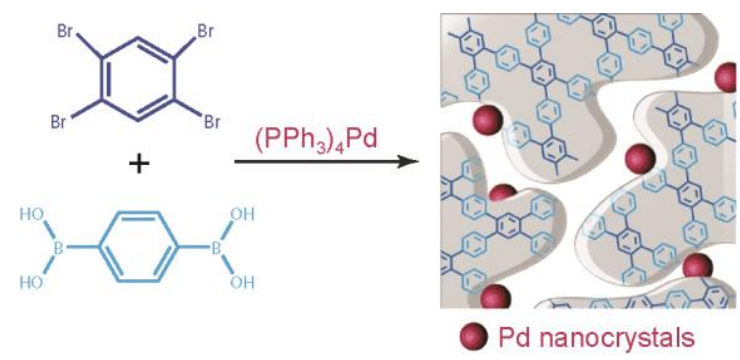

Scheme 1. Scheme for the formation of $\mathrm{Pd} / \mathrm{PPhen}$ by $\left(\mathrm{Ph}_{3} \mathrm{P}\right)_{4} \mathrm{Pd}$-catalyzed coupling of 1,2,4,5-tetrabromobenzene and benzene-1,4-diboronic acid.

After 20 hours of reaction at $150^{\circ} \mathrm{C}$, the cross-coupling reaction results in a gray solid which can be readily isolated from the reaction medium. All reflections in the X-ray diffraction (XRD) pattern can be assigned to palladium nanocrystals, indicating the amorphous character of the polyphenylene polymer (Figure S2). 
Under standard reaction conditions, the palladium loading in the resulting solid is $2.7 \mathrm{wt} \%$; this can be varied by simply adjusting the molar ratio of $\mathrm{Pd}\left(\mathrm{PPh}_{3}\right)_{4}$ to $\mathrm{C}-\mathrm{C}$ coupling substrates in the reaction media (Figure S3). Performing the reaction at a lower temperature of $100{ }^{\circ} \mathrm{C}$ produced the Pd-free polymer ${ }^{[20]}$ (Figure S4). Figure 1 provides an overview of the structure of a $2.7 \mathrm{wt} \% \mathrm{Pd} / \mathrm{PPhen}$ composite. Scanning electron microcopy (SEM) shows irregularly shaped particles with a smooth, highly curved surface. Highresolution scanning-transmission electron tomography (HR-STEM tomography) ${ }^{[21,22]}$ reveals very small Pd-nanoparticles in the size range of 0.5-4 nm (Figure S5), evenly distributed throughout the polymer host. Quantitative analysis of the tomograms shows that $87 \%$ of the Pd-nanoparticles are confined within the polymer network. A representative HR-STEM tilt series is given as Movie S1.
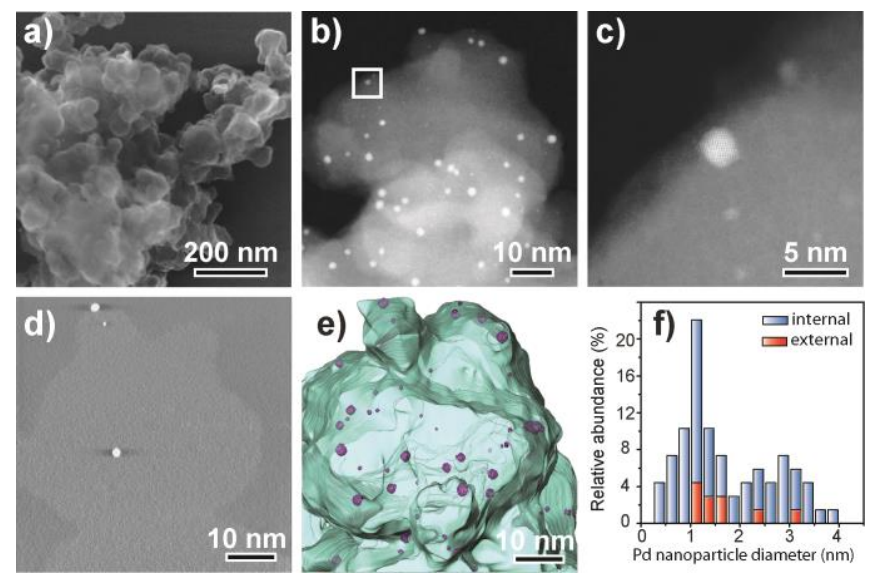

Figure 1. Structure of a Pd/PPhen solid composite (2.7 wt\% Pd). a) Scanning electron micrograph, b) high-angle annular dark-field scanning transmission electron micrographs (HAADF-STEM), c) high-magnification detail of the region framed in panel b. d) cross-sectional slice $(0.12 \mathrm{~nm}$ thick) through the reconstructed HAADF-STEM tomogram. Carbon film of the microscopy grid (darker gray background), PPhen (light gray silhouette), Pd (white). e) 3D, surface-rendered view of the reconstructed HAADF-STEM tomogram after segmentation of the different phases. f) Pd particle size and spatial location histogram.

The solid-state ${ }^{13} \mathrm{C}$ nuclear magnetic resonance $\left({ }^{13} \mathrm{C}\right.$-NMR) spectrum of the solid shows two signals at 140.3 and $129.6 \mathrm{ppm}$, which correspond to the connecting and non-connecting carbon atoms of the polyphenylene, respectively (Figure 2a). Thermogravimetric analysis (TGA) proves the outstanding stability, with no evident mass loss up to ca. $400{ }^{\circ} \mathrm{C}$ in air and up to $600{ }^{\circ} \mathrm{C}$ in argon atmospheres, respectively (Figure 2b). BET-equivalent specific surface area is $1010 \mathrm{~m}^{2} / \mathrm{g}$, of which ca. $10 \%$ corresponds to the external surface of the polymer particles. A total pore volume of $0.46 \mathrm{~cm}^{3} / \mathrm{g}$ results from equal contributions in the micropore $(<1.5$ $\mathrm{nm})$ and supermicropore $(1.5 \sim 2 \mathrm{~nm})$ size ranges. The palladium is accessible, since treatment of the Pd/PPhen composite in solutions of $\mathrm{H}_{2} \mathrm{O}_{2}$ and $\mathrm{HCl}^{[23]}$ results in the quantitative leaching of the metal, so that a Pd-free polymer residue is obtained (Figure S6). The accessibility is due to the micropores and swelling of PPhen. The $\mathrm{Pd} / \mathrm{PPhen}$ composite has a density of $1.38 \pm 0.01 \mathrm{~g} \cdot \mathrm{cm}^{-3}$ and is readily dispersed in all common organic solvents (Table S1). The synthesis has been repeated many times and properties were found to be highly reproducible even at the gram scale.

Suzuki C-C coupling reactions are among the most important reactions in organic synthesis. ${ }^{[4,24]}$ They are mostly carried out in homogeneous phase, catalyzed by palladium complexes such as $\mathrm{Pd}\left(\mathrm{PPh}_{3}\right)_{4}$. Due to the exclusively aromatic backbone of the polyphenylene carrier, favorable interaction of the substrates with the surface of the porous support was expected, which should lead to good catalytic performance.
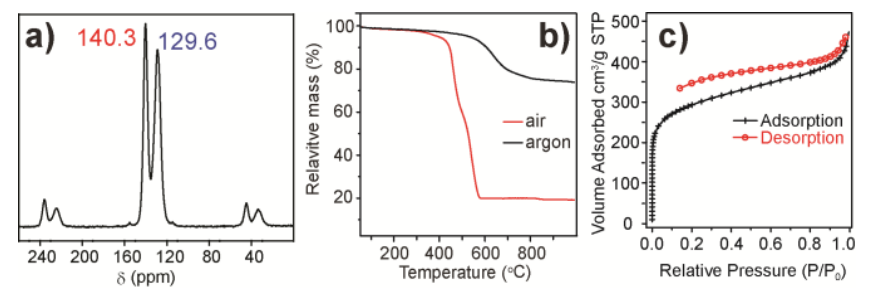

Figure 2. a) Solid-state ${ }^{13} \mathrm{C}$ NMR spectrum. b) TGA profiles in air and argon flow. c) $\mathrm{N}_{2}$-physisorption isotherm.

Initially, coupling between 4-chlorotoluene and phenylboronic acid was studied, where steric requirements are not very demanding; however, chloroaromatic compounds are difficult to activate. ${ }^{[25]}$ $\mathrm{Pd}\left(\mathrm{PPh}_{3}\right)_{4}$ is known to be active for this reaction in organic phase. Similar to its molecular counterpart, $\mathrm{Pd} / \mathrm{PPhen}$ is highly active for this reaction (Table 1, entry 1). In addition to ethanol/water, pure water was also studied as solvent, which facilitates work-up of the reaction mixture. Polyvinylpyrrolidone (PVP, MW $=55,000$ ) was added to facilitate dispersion of $\mathrm{Pd} / \mathrm{PPhen}$ in water, and similar activity was observed (entry 2). $5.9 \mathrm{wt} \% \mathrm{Pd} / \mathrm{PPhen}$ results in a lower yield (entry 3 ) indicating that the larger Pd nanocrystals $(3.3 \pm 0.8$ $\mathrm{nm}$ ) in this composite (Figure S3) are less efficient catalysts. The reactivity of the $\mathrm{Pd} / \mathrm{PPhen}$ solids cannot be attributed to residual $\mathrm{Pd}\left(\mathrm{PPh}_{3}\right)_{4}$ species, since solid-state ${ }^{31} \mathrm{P}$ NMR spectroscopy ruled out the presence of $\mathrm{Pd}\left(\mathrm{PPh}_{3}\right)_{4}$ residues in the solid catalyst. Moreover, XPS of the Pd/PPhen solid shows two signals corresponding to $\operatorname{Pd}(0) 3 \mathrm{~d}_{5 / 2}(335.9 \mathrm{eV})$ and $3 \mathrm{~d}_{3 / 2}(341.2 \mathrm{eV})$ (Figure S7), confirming the metallic character of the palladium species.

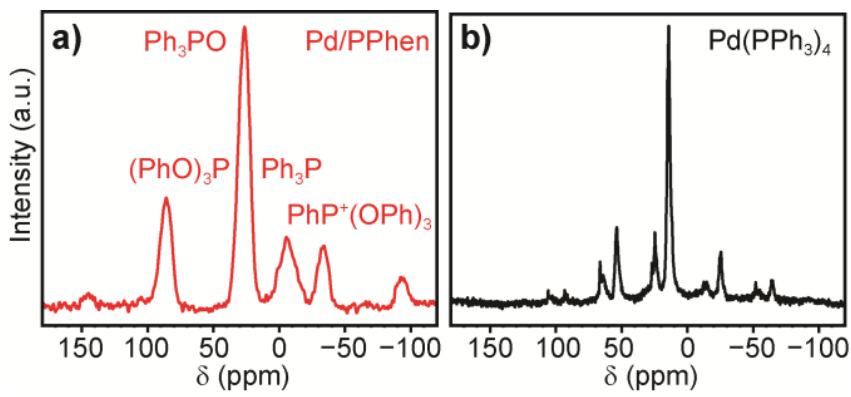

Figure 3. Phosphorus speciation as studied by solid-state ${ }^{31} \mathrm{P} N \mathrm{NM}$ spectroscopy. a) $\mathrm{Pd} /$ Phen composite. b) commercial solid $\mathrm{Pd}\left(\mathrm{PPh}_{3}\right)_{4}$.

Other solid and molecular Pd-catalysts, including $\mathrm{Pd}$ nanoparticles (2.7 wt \%, Pd particle size in the range of $0.5-3.5 \mathrm{~nm}$ ) on either carbon or PDVB carriers prepared through impregnation with the $\mathrm{Pd}\left(\mathrm{PPh}_{3}\right)_{4}$ precursors followed by reduction in $\mathrm{H}_{2}$ (Figure $\mathrm{S} 8$ and S9), gave rather poor results (entries 4-8). $\mathrm{Pd} / \mathrm{C}$ and $\mathrm{Pd} / \mathrm{PDVB}$ obtained via precipitation in DMF at $150{ }^{\circ} \mathrm{C}$ also give no conversion. The superior performance strongly suggests a synergistic role of the PPhen support material for the catalytic performance. This might be attributed to its unique conjugated aromatic structure, which is absent in carbon and PDVB, and which might allow for strong $\pi-\pi$ interactions with the substrates in the vicinity of the catalytic palladium species, similar to the proposed 
effect of conjugated aromatic ligands in $\mathrm{C}-\mathrm{C}$ coupling reactions catalyzed by palladium complexes. ${ }^{[25]}$

Table 1. Suzuki coupling reactions using different Pd catalysts.

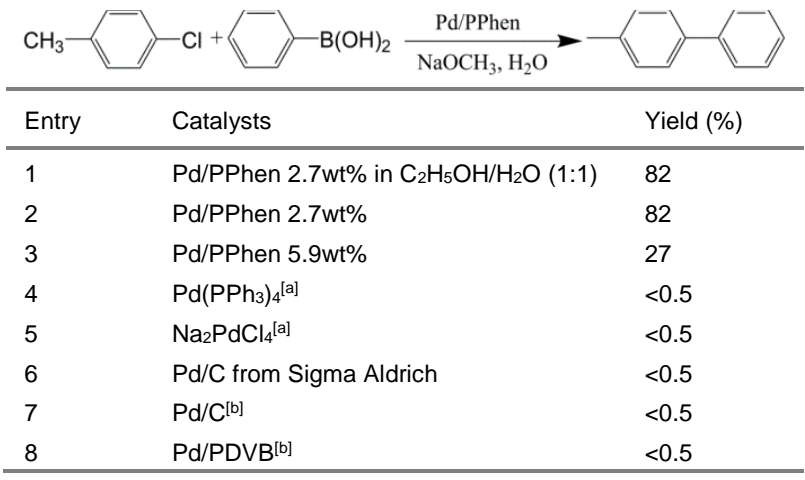

Reaction conditions: chlorotoluene $0.5 \mathrm{mmol}$, phenylboronic acid $0.75 \mathrm{mmol}$, $\mathrm{NaOCH}_{3} 1.5 \mathrm{mmol}$, catalyst ( $0.8 \mathrm{~mol} \% \mathrm{Pd}$ to aryl chloride), PVP $0.5 \mathrm{mg}$, water 5 $\mathrm{mL}, 80^{\circ} \mathrm{C}$, under argon, 3h. ${ }^{[a]}$ Tetrabutylammonium bromide (TBAB) ${ }^{[30]} 0.3$ $\mathrm{mmol}$ is added as phase transfer catalyst. ${ }^{[b]} \mathrm{Pd} / \mathrm{C}$ and $\mathrm{Pd} / \mathrm{PDVB}$ are prepared via methods indicated in supporting information.

The superior catalytic activity of the Pd/PPhen composite over all other systems studied ${ }^{[26,27]}$ encouraged us to explore the performance with more challenging Suzuki coupling reactions, such as with 2-chloro-1,3-dimethylbenzene or 4-chloroanisole. These substrates require more effective ligands in molecular catalysis, such as $\mathrm{N}$-heterocyclic carbenes, $\mathrm{P}(t \mathrm{Bu})_{3}$ or the phosphine family developed by Buchwald and co-workers. ${ }^{[25,28,29]}$ These substrates are known to pose an even greater challenge to heterogeneous catalysis. ${ }^{[26]} \mathrm{Pd} / \mathrm{PPhen}$ as catalyst in the Suzuki coupling reaction of 2-chloro-1,3-dimethylbenzene with arylboronic acid results in a yield above $50 \%$ after only three hours (Table 2, entry 1). Yields exceeding $80 \%$ are obtained for other unactivated substrates after 20 $\mathrm{h}$ (entries 3,5). The results indicate that PPhen may act as a conjugated ligand in a similar manner as the Buchwald ligands to stabilize the transition state of the oxidative addition and/or reductive elimination.

Table 2. Suzuki coupling reactions using different substrates.

Entry Aryl choride

Reaction conditions: aryl chloride $0.5 \mathrm{mmol}$, arylboronic acid $0.75 \mathrm{mmol}$ $\mathrm{NaOCH}_{3} 1.5 \mathrm{mmol}$, catalyst ( $0.8 \mathrm{~mol} \% \mathrm{Pd}$ to aryl chloride), PVP $0.5 \mathrm{mg}$, water 5 $\mathrm{mL}, 80^{\circ} \mathrm{C}$, under argon.

The nature of the "true" catalytic species in Suzuki coupling reactions has been long debated. Very recently, Corma and coworkers showed that ligand-free, very small palladium clusters are responsible for the catalytic activity in aqueous media. ${ }^{\left[{ }^{30]}\right.}$ Under our experimental conditions, removal of the solid catalyst from the reaction media via hot filtration revealed that neither product nor 4chlorotoluene was present in the remaining solution (for analysis, reactants and products were extracted, see Experimental details). This supports the notion that the PPhen solid carrier locally provides an organic solvent-like environment. When fresh 4-chlorotoluene and phenylboronic acid substrates and base were added into this solid-free solution, along with $\mathrm{TBAB}$ to transfer 4-chlorotoluene into the aqueous phase, no reaction was detected after $3 \mathrm{~h}$ at $80^{\circ} \mathrm{C}$. Elemental analysis of the hot filtered solution gave palladium concentrations below $10 \mathrm{ppm}$. Accordingly, the $\mathrm{Pd} / \mathrm{PPhen}$ catalyst could be recylced, retaining product yields in the range of $78-84 \%$ for four recycles (Table S2 and Figure S10).

Polyphenylene thus holds high promise as C-C coupling catalyst and for different gas phase reactions which are currently being explored in our laboratory.

Received: ((will be filled in by the editorial staff))

Published online on ((will be filled in by the editorial staff))

Keywords: Polymer support • Polyphenylene • One pot synthesis • Palladium nanoparticles $\bullet$ Suzuki coupling

[1] D. Astruc, F. Lu, J. R. Aranzaes, Angew. Chem. 2005, 117, 8062 8083; Angew. Chem. Int. Ed. 2005, 44, 7852-7872.

[2] C. A. Witham, W. Y. Huang, C.-K. Tsung, J. N. Kuhn, G. A. Somorjai, F. D. Toste Nat. Chem. 2010, 2, 36-41.

[3] I. N. Lykakis, A. Psyllaki, M. Stratakis, J. Am. Chem. Soc. 2011, 133, 10426-10429.

[4] N. Miyaura, A. Suzuki, Chem. Rev. 1995, 95, 2457-2483.

[5] R. Martin, S. L. Buchwald, Acc. Chem. Res. 2008, 41, 1461-1473.

[6] J. K. Stille, Angew. Chem. 1986, 98, 504-519; Angew. Chem. Int. Ed. 1986, 25, 508-523.

[7] N. E. Leadbeater, M. Marco, Chem. Rev. 2002, 102, 3217-3273.

[8] J. Lu, P. H. Toy, Chem. Rev. 2009, 109, 815-838.

[9] H. Miyamura, R. Matsubara, Y. Miyazaki, S. Kobayashi, Angew. Chem. 2007, 119, 4229-4232; Angew. Chem. Int. Ed. 2007, 46, 4151-4154.

[10] S. N. Sidorov, I. V. Volkov, V. A. Davankov, M. P. Tsyurupa, P. M. Valetsky, L. M. Bronstein, R. Karlinsey, J. W. Zwanziger, V. G. Matveeva, E. M. Sulman, N. V. Lakina, E. A. Wilder, R. J. Spontak J. Am. Chem. Soc. 2001, 123, 10502-10510.

[11] F. H. Richter, Y. Meng, T. Klasen, L. Sahraoui, F. Schüth, J. Catal. 2013, 308, 341-351.

[12] C. Burato, P. Centomo, G. Pace, M. Favaro, L. Prati, B. Corain J. Mol. Catal. A: Chem. 2005, 238, 26-34

[13] R. Palkovits, M. Antonietti, P. Kuhn, A. Thomas, A. F. Schüth, Angew. Chem. 2009, 121, 7042-7045; Angew. Chem. Int. Ed. 2009, 48, 69096912.

[14] A. Dhakshinamoorthy, H. Garcia, Chem. Soc. Rev. 2012, 41, $5262-$ 5284.

[15] B. Z. Yuan, Y. Y. Pan, Y. W. Li, B. L. Yin, H. F. Jiang, Angew. Chem 2010, 122, 4148-4152; Angew. Chem. Int. Ed. 2010, 49, 4054-4058.

[16] M. Sabo, A. Henschel, H. Fröde, E. Klemm S. Kaskel, J. Mater. Chem. 2007, 17, 3827-3832. 


\section{Angewandte}

\section{Communications}

[17] L. R. Radovic, F. Rodriguez-Reinoso, Chemistry and physics of carbon, vol 25. ( Thrower,PA, 1997).

[18] T. Yamamoto, K. Osakada, T. Wakabayashi, A. Yamamoto, Makromol. Chem-Rapid 1985, 6, 671-674.

[19] A. D. Schluter, G. Wegner, Acta Polym. 1993, 44, 59-69.

[20] L. Chen, Y. Honsho, S. Seki, D. L. Jiang, J. Am. Chem. Soc. 2010 , 132, 6742-6748.

[21] G. Prieto, J. Zecevic, H. Friedrich, K. P. de Jong, P. E. de Jongh, Nat. Mater. 2013, 12, 34-39.

[22] J. Zečevič, K P. de Jong, P. E. de Jong, Curr. Opin. Solid State Mater. Sci. 2013, 17, 115-125.

[23] C.-K. Tsung, X. S. Kou, Q. H. Shi, J. P. Zhang, M. H. Yeung, J. F. Wang, G. D. Stucky J. Am. Chem. Soc. 2006, 128, 5352-5353.
[24] X.-F. Wu, P. Anbarasan, H. Neumann, M. Beller, Angew. Chem. 2010, 122, 9231-9234; Angew. Chem. Int. Ed. 2010, 49, 9047-9050.

[25] A. F. Littke, G. C. Fu, Angew. Chem. 2002, 114, 4350-4386; Angew. Chem. Int. Ed. 2002, 41, 4176-4211.

[26] L. X. Yin, J. Liebscher, Chem. Rev. 2007, 107, 133-173.

[27] A. Balanta, C. Godard, C. Claver, Chem. Soc. Rev. 2011, 40, 49734985.

[28] D. W. Old, J. P. Wolfe, S. L. Buchwald, J. Am. Chem. Soc. 1998, 120, 9722-9723.

[29] S. D. Walker, T. E. Barder, J. R. Martinelli, S. L. Buchwald, Angew. Chem. 2004, 116, 1907-1912; Angew. Chem. Int. Ed. 2004, 43, 1871 1876.

[30] A. Leyva-Pérez, J. Oliver-Meseguer, P. Rubio-Marqués, A. Corma, Angew. Chem. 2013, 125, 11768-11773; Angew. Chem. Int. Ed. 2013, $52,11554-11559$ 


\section{Angewandte \\ Communications}

Entry for the Table of Contents (Please choose one layout)

Layout 1:

\section{Polymeric Catalysts}

Author(s), Corresponding Author(s)*

$$
\text { Page - Page }
$$

A Polyphenylene Support for $\mathrm{Pd}$ Catalysts with Exceptional Catalytic Activity

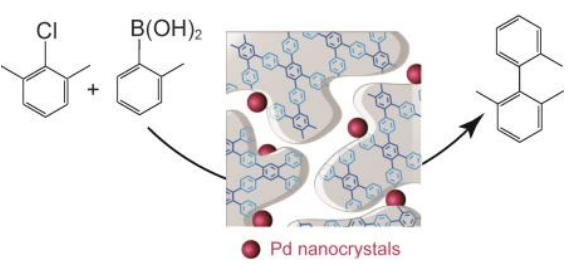

A polyphenylene support as an excellent platform is developed for metal catalyzed reactions, which are typically carried out under homogeneous conditions. 